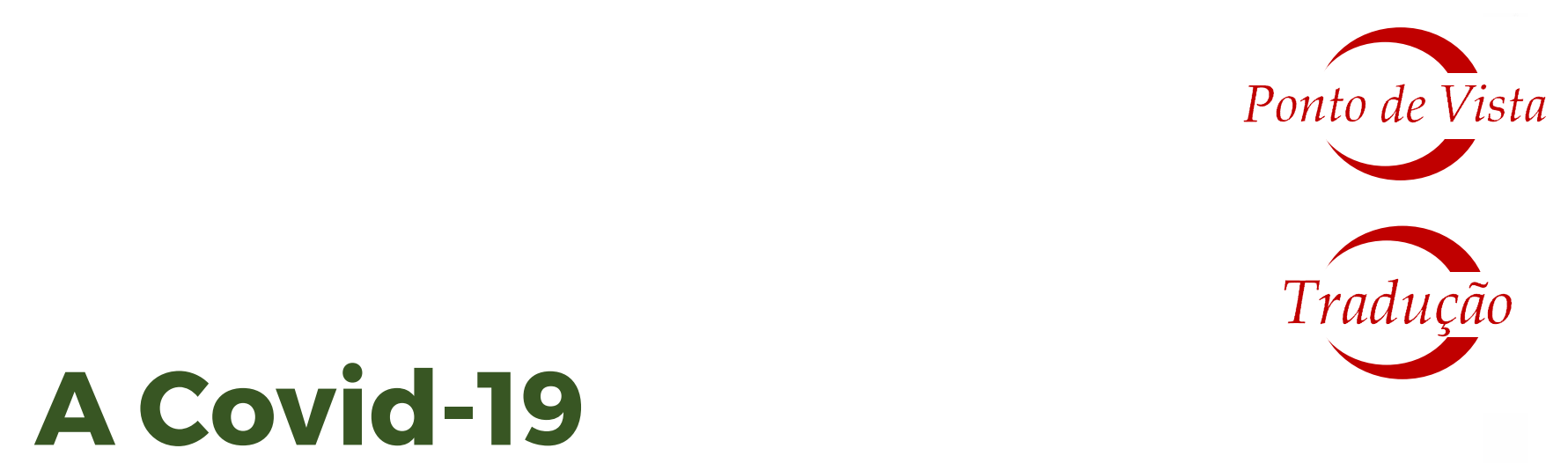

e as perturbações no presentismo
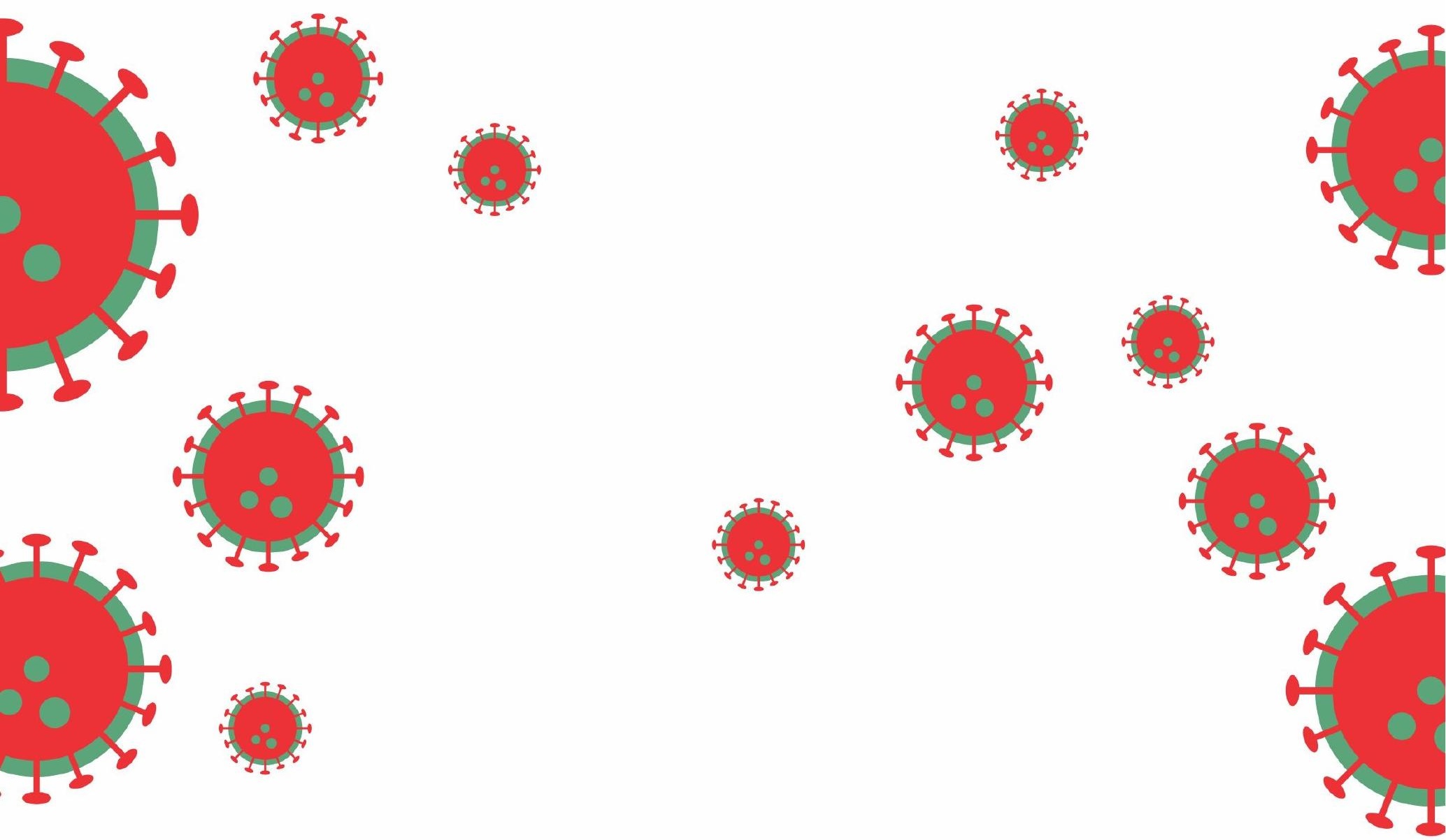

\title{
François Hartog
}

Doutor em Historiografia Antiga e Moderna pela École Normale Supérieure (ENS-Paris). Professor de História Antiga e Moderna na École des Hautes Études en Sciences Sociales (Ehess/França). Autor, entre outros livros, de Regimes de historicidade: presentismo e experiências do tempo. Belo Horizonte: Autêntica, 2013. francois.hartog@ehess.fr
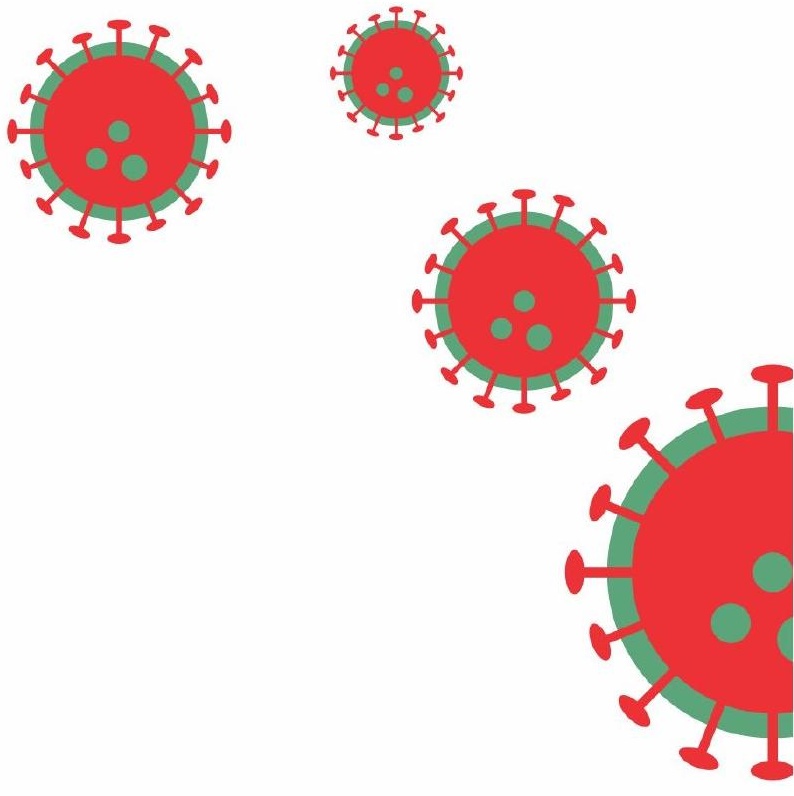
A Covid-19 e as perturbações no presentismo*

Trouble dans le présentisme: le temps du Covid-19

François Hartog

Tradução: Fernando Alvim**

Revisão técnica da tradução: Alexandre de Sá Avelar ${ }^{* * *}$

\section{RESUMO}

Como e se a pandemia do coronavírus provocou uma mudança nas temporalidades que atravessam nosso cotidiano é o que este artigo se propõe analisar. Colocada sob o signo de uma urgência, que nos levou em poucos dias até o "estado de emergência sanitária", a suspensão das atitudes corporais ordinárias (perigosas) e sua substituição por outras (todas, por sua vez, defensivas e protetivas) deveriam operar, como é normal no regime presentista, instantaneamente ou quase. Desde Hipócrates, cabe à medicina reconhecer que a doença tem, ela também, uma temporalidade própria. Sob a desordem aparente da doença, há de fato uma ordem que identifica o olho treinado do médico: uma ordem do tempo. O tempo da pandemia conduziu à instauração de um tempo novo, aquele do confinamento: tempo sanitário, já que o confinamento é o único instrumento à nossa disposição, diz a medicina, para retardar, frear a progressão do vírus, para que a curva exponencial cesse sua implacável ascensão. Nesse ponto, surgem inevitáveis conflitos de temporalidades que pedem arbitragens. A questão da nomeação do acontecimento é central. Epidemia, pandemia, sim, mas nós ficamos na esfera
ABSTRACT

Cet article veut analyser comment - et sila pandémie de coronavirus a provoqué un changement dans les temporalités qui traversent notre quotidien. Placée sous le signe d'une urgence qui nous a menés en quelques jours jusqu'à "l'état d'urgence sanitaire", cette suspension des attitudes corporelles ordinaires (dangereuses) et leur remplacement par d'autres (tout à la fois défensives et protectrices) devraient s'opérer, comme il est normal en régime présentiste, instantanément ou presque. Depuis Hippocrate, il revient à la médecine de reconnaître que la maladie a, elle aussi, une temporalité propre. Sous le désordre apparent de la maladie, il y a en fait un ordre que repère l'ail exercé du médecin : un ordre du temps. Le temps de la pandémie a conduit à l'instauration d'un temps nouveau, celui du confinement: temps sanitaire, puisque le confinement est le seul instrument à notre disposition, dit la médecine, pour retarder, freiner la progression du virus, pour que la courbe exponentielle cesse son implacable ascension. En ce point surgissent d'inévitables conflits de temporalités qui appellent des arbitrages. La question de la nomination de l'événement est centrale. Epidémie, pandémie, oui, mais nous restons dans la sphère de la médecine. La question est de savoir si la crise majeure que traverse le

\footnotetext{
* Publicado originalmente, sob o título de Trouble dans le présentisme: le temps du Covid-19, no jornal diário AOC, Paris, 1 abr. 2020.

** Graduado em Letras/Francês e Estudos Literários pela Universidade Federal de Goiás (UFG). Mestre em Literatura Brasileira pela Universidade de São Paulo (USP). scriptorbrasil@gmail.com

*** Doutor em História pela Universidade Federal Fluminense (UFF). Professor dos cursos de graduação e pós-graduação em História do Instituto de História da Universidade Federal de Uberlândia UFU). Pesquisador do CNPq. Coorganizador, entre outros livros, de $O$ futuro da história: da crise à reconstrução de teorias e abordagens. Vila Velha: Milfontes, 2019. alexandre.avelar@uol.com.br
} 
da medicina. A questão é saber se a grande crise que atravessa o mundo é uma oportunidade, um kairos, que, interrompendo as temporalidades habituais do tempo chronos, poderia abrirse sobre um novo tempo.

PALAVRAS-CHAVE: crise; temporalidades; pandemia. monde est une occasion, un kairos, qui, interrompant les temporalités usuelles $d u$ temps chronos, pourrait ouvrir sur un temps nouveau.

MOTS CLES: crise; temporalités; pandémie.

O que a irrupção do coronavírus mudou em nossas relações com o tempo? Desde que o acontecimento ocorreu subitamente na China (ao menos até onde nos foi possível reportar) pudemos vê-lo chegar enquanto desejávamos acreditar que, talvez, ele tivesse o bom gosto de não se espalhar muito além da Ásia. Mas, uma vez alcançada a Europa e a França, quais perturbações e reconfigurações foram causadas por isso que rapidamente nomeou-se epidemia, e depois pandemia, sabendo-se que ela veio a colidir com o emaranhado de temporalidades já ativas que formam a textura do nosso cotidiano? É apenas sob este ângulo que irei observar a crise que estamos atravessando (este texto foi escrito no final do mês de março de 2020). Eu não sou nem epidemiologista nem mesmo historiador da medicina.

Em apenas algumas semanas, um novo vocabulário, posto em circulação pela opinião pública e transmitido por todas as mídias, entrou no uso cotidiano: "gestos de bloqueio", "distanciamento social", "álcool em gel" e "máscaras" (inevitavelmente "em falta"). "Presencial" e "a distância" ganharam notoriedade para designar uma reunião, conforme os participantes estejam fisicamente presentes ou a distância atrás das suas telas. Em resumo, nada menos do que uma nova disciplina corporal foi instituída, mas sem que tivéssemos tempo para internalizá-la. O que diria Norbert Elias? Que os países onde não é costume apertar a mão ou trocar beijos estariam em vantagem em relação à Covid-19? Raros, enfim, são os detentores de uma fala autorizada que não se sentem, de uma forma ou de outra, obrigados a vangloriar a "resiliência" dos franceses: resiliência instantânea, antecipada ao próprio traumatismo, comparável ao "trabalho de luto", não menos instantâneo, que convém ser realizado imediatamente após uma catástrofe. Sob o signo de uma urgência, que nos levou em poucos dias ao "estado de emergência sanitária", tal suspensão das atitudes corporais ordinárias (perigosas) e sua substituição por outras (simultaneamente defensivas e protetivas) deveriam operar, como é comum no regime presentista, de modo instantâneo ou quase.

Como caracterizar, de forma necessariamente esquemática, o estado do nosso presente? De qual nó de temporalidades diferentes, que se cruzam, se sobrepõem, se opõem, ele é a resultante, sempre em movimento, antes que se produza o choque da epidemia? Ele está, de fato, dividido, senão esquartejado, entre várias temporalidades. A fase conquistadora e otimista do presentismo, aquela que ocorreu há vinte ou vinte e cinco anos, ficou para trás. Hoje se trata, sobretudo, da perturbação no presentismo. Denuncia-se seu curto 
prazo e considera-se a extensão dos danos que ele gerou. Isso não impede que, no mesmo instante, a extensão do digital, sob suas múltiplas declinações, em que a unidade de conta é o nano-segundo, incite ou obrigue os indivíduos e as instituições a viverem cada vez mais sob o regime do imediatismo.

A esse primeiro conflito soma-se outro, cada vez mais urgente e até mesmo opressivo, aquele que surgiu há apenas dez anos entre os diversos tempos do mundo e o tempo do antropoceno. ${ }^{1}$ Um pouco como a estátua do comandante em Dom Juan ou le Festin de Pierre, de Molière, o antropoceno convidou-se à nossa mesa, com a diferença de que ninguém o havia chamado! De um lado, o futuro parece ser aquele da emergência de uma condição digital que tenta conservar ou dar um rosto humano ao devir; de outro, o futuro próximo parece ser chamado a engolir a si próprio dentro de um tempo, um tempo chronos que escapa a toda captura, já que ele se conta em milhões ou bilhões de anos. Passamos do registro do conflito de temporalidades àquele da franca contradição, sem que vejamos como poderíamos reduzi-la.

Que faz, então, se ouso propor outra imagem, a bola da epidemia, logo requalificada em pandemia, no jogo de boliche das temporalidades usuais? Primeiro efeito: o presente da epidemia apressa e depois estabiliza pouco a pouco os tempos da vida ordinária (tempo escolar, tempo do trabalho, dos lazeres etc.). Mas, desde Hipócrates, cabe à medicina reconhecer que a doença tem uma temporalidade própria. A arte médica é precisamente um pensamento da crise. Por crise, entendem-se os momentos decisivos ou, ao menos, significativos do curso de uma doença. Depois de feito o diagnóstico, segue-se o prognóstico, isto é, o estabelecimento do ritmo da crise com seus picos, chamados de "dias críticos", em relação aos quais é essencial definir a periodicidade. Pois, sob a desordem aparente da doença, há de fato uma ordem que o olho treinado do médico identifica: uma ordem do tempo. É bem isso que fazem as autoridades médicas que nos apresentam, dia após dia, as curvas (ainda exponenciais) indicando a evolução da doença. Elas também vigiam os "dias críticos": o pico. Às 19 horas, todas as noites, o ponto numérico do professor Jérôme Salomon recoloca nossos relógios na hora imperiosa da epidemia. Como diretor geral da Saúde, ele se encontra localizado na interface entre o tempo da doença, do qual ele é o intérprete, e o tempo político, que ele não pode ignorar. As intervenções em parceria com o Ministro da Saúde são uma encenação disso.

Se nós temos, com Hipócrates, uma teoria de crise por meio de sua temporalização (sob a desordem aparente, há uma ordem temporal), nós dispomos, com outro grego, Tucídides, de uma primeira descrição de uma epidemia, a "peste" que atingiu Atenas em 430 antes da nossa era. Leiam-na ou a releiam, tanto mais porque ela inspirou, direta ou indiretamente, a maioria das descrições posteriores das pestes. Camus se lembrou dela. Eu recordarei apenas um traço: aquele da situação de "anomalia" que ganha a cidade. Tucídides nota o transtorno dos costumes e a desordem dos comportamentos. Os ritos funerários não podiam mais ser realizados; assim, "cada um sepultava como podia". De que adianta lutar por um objetivo elevado, quando se podia

\footnotetext{
${ }^{1}$ Nota do tradutor: antropoceno é um termo usado por alguns cientistas para descrever o período mais recente na história do planeta Terra.
}

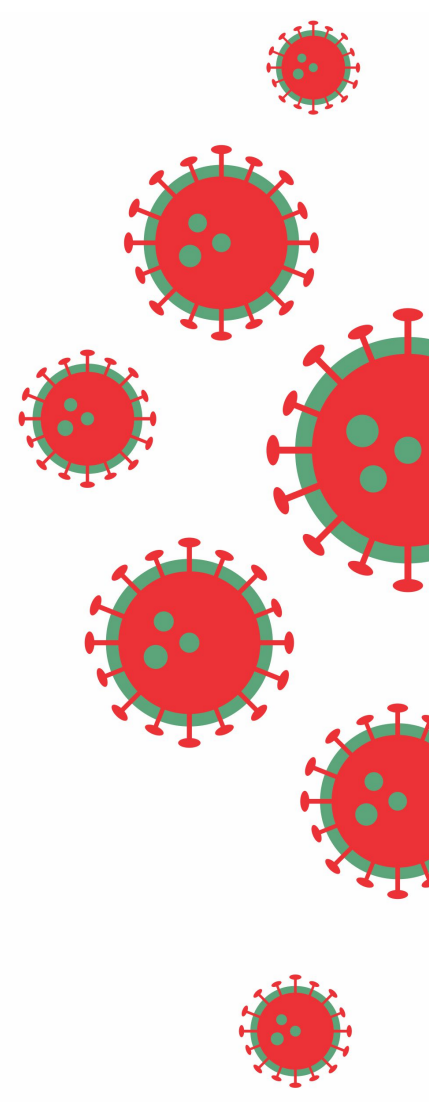


estar morto no dia seguinte? “O prazer imediato [...] eis o que tomou o lugar e do belo e do útil”. Muito felizmente, nós não estamos lá!

O tempo da pandemia conduziu à instauração de um tempo novo, o do confinamento: tempo sanitário, já que o confinamento é o único instrumento à nossa disposição, diz a medicina, para retardar, frear a progressão do vírus, cessar a implacável ascensão da curva exponencial. Ganhar tempo, retardando-o, eis o que poderia espantar à primeira vista, ainda que apenas sonhemos em nos livrarmos dele o mais rápido. Deste tempo, os médicos entendiam ser os únicos gestores (daí as chamadas urgentes de alguns para um confinamento total). Porém, o tempo do confinamento é também um tempo eminentemente social e, portanto, político, do qual as autoridades políticas não pretendem abrir mão. Nesse ponto, surgem inevitáveis conflitos de temporalidades que demandam arbitragens, e o Conselho Científico é provavelmente a instância ad hoc para elaborá-las. A questão da nomeação do acontecimento é central. Epidemia, pandemia, sim, mas nós permanecemos na esfera da medicina, e o presidente da República destruiu um trunfo fundamental declarando o estado de guerra. Quem diz guerra diz tempo de guerra, que se torna, da mesma maneira, o tempo mais abrangente e disponível ao poder político.

A nova disciplina corporal esboçada acima é concebida, antes de tudo, para o exterior. De qual disciplina de vida e de qual relação com o tempo o confinamento é o instrumento? Etimologicamente, o confinamento é um caso de limite e de fronteira. Ademais, neste momento exato, interrogamo-nos sobre os limites dos nossos deslocamentos (a quantos metros de nossa casa?). $\mathrm{O}$ confinamento teve dois sentidos, de acordo com o que se confina ou o que é confinado. No primeiro caso, confinar-se é retirar-se; no segundo, é ser relegado e pode equivaler a uma morte civil. Concebe-se perfeitamente que o confinamento, ou sua ameaça, suscita imediatamente o desejo de fugir entre aqueles que têm os meios para fazê-lo: para escapar à epidemia, para abrigar-se (ou acreditar nisso), para se confinar e não ser confinado, para se isentar em parte dos rigores do tempo do confinamento. Em 1348, em Florença, enquanto a peste reinava no domínio da morte, dez jovens fugiram da cidade para um palácio nas encostas de Fiesole, e lá se entregaram, durante duas semanas, aos prazeres das histórias de amor. Conforme o tema dado pelo rei ou a rainha do dia, cada um devia, a cada dia, contar uma história. Boccaccio era o escriba, ou seja, o autor, e com seu Decameron, que muito rapidamente conheceu um grande sucesso, nascia um novo gênero literário: o conto. Nós veremos se, da massa de escritos já produzidos, difundidos gradativamente, e que aumentam a cada dia, sairão renovações literárias. A Ilha de Ré ou o Luberon desempenharão o papel do espaço utópico encenado por Boccaccio? Mas aí está o confinamento à moda antiga, já que a tecnologia atual transformou profundamente o seu significado espacial e, permitindo transpor a fronteira - com o teletrabalho, o tele-ensino, a teleconsulta, toda uma "telessociabilidade", se não uma telessociedade -, ela acelera nossa mutação digital.

Espacial, o confinamento é também temporal: com ele se instaura um tempo inédito. Até então, a Covid-19, invadindo mais e mais o espaço midiático, era como uma série da qual se desejava ver desfilar, aceleradamente, todas as temporadas. Todavia, o confinamento, uma vez decretado, muda tudo e nós mesmos nos tornamos personagens dessa série. Submissos ao tempo da pandemia, nós devemos habitar o tempo do confinamento: estabelecer empre- 
gos do tempo (os conselhos não faltam), ritmá-lo (algumas saídas ainda são autorizadas), preenchê-lo, marcar tempos fortes (os aplausos às 20h, endereçados aos profissionais cuidadores, à fala presidencial). Resumindo, precisamos forjar, cada um por sua própria conta, uma ordem do tempo não muito desarticulada, se possível, de um tempo coletivo que procura manter as diversas instituições, a começar pelo poder executivo.

No mais, o confinamento não fez desvanecer o presentismo ambiente, mas, antes de tudo, o reforçou. Trata-se, de fato, de um confinamento conectado, não tanto de um retiro solitário. Toda a tecnologia está aí: nós podemos fazer um tour pelo mundo sem sair de nosso quarto, partilhar aperitivos pelo WhatsApp com todos os nossos amigos, ouvir um concerto em Viena ou em Berlim, ler durante horas a fio na $\mathrm{BNF}^{2}$, seguir a cada instante o que está acontecendo. Ver tudo, ouvir tudo, estar presente em tudo, falta apenas a presença. Há, contudo, outro confinamento, o de todos aqueles que não estão conectados ou daqueles cujo normal é o das redes sociais. A fratura digital atravessa também o confinamento e as relações com tempo que ele induz, inclusive as recusas ou as negações daqueles que apontamos como os "recalcitrantes" do confinamento.

Enfim, há aqueles e aquelas que, estando oficialmente sob o regime do confinamento, devem trabalhar efetivamente. Produz-se, então, um outro conflito de temporalidades. Eles têm, por assim dizer, um pé no antigo tempo e outro no tempo novo. Mais amplamente, o tempo da pandemia atropelou o tempo da economia. Às curvas exponenciais da primeira responderam as curvas imergentes da segunda. Dessa queda, ampliada pelos mercados com seu olho no imediato, os efeitos estão largamente por vir, fazendo erguer-se a questão do depois.

Entre o tempo da doença monitorada pelos médicos e a emergência uma das palavras-chave do presentismo - surgiu um conflito de temporalidades que se cristalizou em torno do problema da elaboração de um tratamento curativo e de uma vacina. No roteiro de uma série, o pesquisador genial e marginalizado descobriria a molécula certa que, no último momento, salvaria a humanidade. E na realidade?

O ponto sobre o qual todos concordam é o da aceleração: é necessário, repete-se, "acelerar" os testes clínicos, acelerar os procedimentos de validação etc. No entanto, até que ponto o tempo dos protocolos científicos é compressível sem a perda de sua capacidade de validação? A esperança de um tratamento e, mais tarde, de uma vacina, viria, vem interromper o curso inexorável do tempo da pandemia e mostra um horizonte. Porém, em nome da indiscutível urgência, desejar-se-ia, deseja-se que esse horizonte não somente se aproxime o mais rápido, mas esteja já aqui. Para alguns, ele já está aí. Eu ignoro até que ponto eles estão errados ou têm razão, mas o imediatismo da urgência tende a suplantar todas as outras temporalidades. Na esteira da urgência, também vêm o atraso, o tempo do atraso, o tarde demais. A urgência é uma corrida previamente sem fim: para não ser ultrapassado, é necessário agir sem cessar antes que seja tarde demais. Haverá sempre alguém, bem ou mal inten-

2 Nota do tradutor: Biblioteca Nacional da França. 
cionado, para denunciar o atraso. Entretanto, quando a urgência é onipresente, como hierarquizar as urgências?

Para além do tempo da doença e do seu horizonte, cabe ao presidente da República esboçar - ou, ao menos, se esforçar para isso - um devir mais amplo para os seus concidadãos. É indispensável indicar um após, quando o tempo de guerra se for e o vírus tiver desaparecido. De fato, ele começou a falar de um antes e de um depois da crise, um depois que não poderá ser a simples reprise do antes. Em vários pontos, deixa a desejar, mas veremos o que acontece em relação a isso. Em todo caso, é certo que não se arbitra o fim do presentismo por decreto, e nós acabamos de observar que o tempo do confinamento é, por sua vez, um questionamento do presente único e um fortalecimento do domínio do presentismo por meio da tecnologia, para a qual apelamos mais do que nunca.

No início, abordei a contradição entre nosso presente presentista e o tempo incrivelmente longo do antropoceno. Se ela perdeu sua visibilidade midiática no curso das últimas semanas, nada disso desapareceu, e ouso dizer que ela nos espera resistindo firmemente. Vários daqueles que se preocupam com isso e que buscam há muito tempo nos convencer de que nosso verdadeiro horizonte é o do aquecimento global, para atribuir-lhe seu nome comum, convidam-nos a aproveitarmos a crise mundial provocada pelo coronavírus para, após o confinamento, adotarmos "uma estratégia mais ambiciosa", ingressando em uma "resistência climática" (Le Monde, 19 mar. 2020). Além das referências às palavras "guerra' e "resistência", a questão é saber se a grande crise que atravessa o mundo é uma oportunidade, um kairos, que, ao interromper as temporalidades usuais do tempo chronos, poderia se abrir sobre um novo tempo. ${ }^{3}$ Talvez o seu início? Ou, ao contrário, é a stasis (para retomar outro velho conceito grego) que se impõe, com suas temporalidades bem conhecidas e mais ou menos imperiosas, aos conflitos políticos, às lutas sociais mais ou menos exacerbadas e violentas, ou mesmo à guerra civil? 